Session 2793

\title{
Assessing the Effectiveness of Computer Literacy Courses
}

\author{
Robert Lingard, Roberta Madison, Gloria Melara \\ California State University, Northridge
}

\begin{abstract}
Computer literacy is growing in importance for all university students and is especially important for students pursuing technical and engineering courses of study. While an increasing number of today's students enter the university with an adequate level of computer knowledge and skill, there are many who do not. Large numbers of students, especially from economically disadvantaged communities, lack the computer skills necessary to be successful in most engineering programs. Therefore, it is particularly important for universities to offer computer literacy courses to accommodate the needs of such students. In order to ensure the effectiveness of educational programs in computer literacy, assessment must be done on a continuing basis. Such assessment has been difficult due to varying definitions of computer literacy and the lack of tools to adequately assess such programs. This paper describes a pilot study conducted at California State University, Northridge that was done as an experimental attempt to assess the effectiveness of computer literacy courses. The specific instruments used as well as others investigated are discussed, and the methods of conducting the assessment are explained. The results of the pilot study are presented along with recommendation for the development of improved instruments and methods for computer literacy assessment.
\end{abstract}

\section{Introduction}

Computer literacy has received a significant amount of attention in recent years. While computer literacy is important for all university students, it is essential for students pursuing technical and engineering courses of study. Although many of today's students enter the university with an adequate level of computer knowledge and skill, large numbers of students, especially from economically disadvantaged communities, lack the computer skills necessary to be successful in most engineering programs. "Despite the incredible growth of the Internet since the early 1990s, many citizens still do not have easy access to basic Information Technology tools, including hardware, software, or the Internet itself. Access is an issue that affects people at home, at school 
and in the community-at-large. Neighborhoods with less access to technology are at a disadvantage in contrast to those neighborhoods with more access when it comes to seeking better education, better jobs, even higher levels of civic participation" [1].

According to a report [2] issued by the U.S. Department of Commerce, only 23.6 percent of Hispanic households had access to the Internet compared to 41.5 percent of all households. Although this number for Hispanics more than doubled in the period from December 1998 to August 2000, the gap between Hispanics and the national average widened from 13.6 percent to 17.9 percent. Since California State University, Northridge (CSUN) is a federally designated Hispanic Serving Institution (HSI), this is a problem of particular concern. Hispanic students entering CSUN are much less likely to be computer literate than students of other ethnicities. Especially in technical fields where computer skills are essential for success, the university must provide effective computer literacy courses to meet the needs of students. Developing tools to assess learning outcomes is mandatory to ensure that students are gaining the computer knowledge and skills they need to be successful in their chosen fields of study.

Programs have been developed for teaching computer literacy, but little has been done to test their efficacy. One problem in assessing such programs is that there is no generally accepted definition of computer literacy. The Webster's II New College Dictionary [3] defines computer literacy as "the ability to use a computer and its software to accomplish practical tasks." Stewart [4] says computer literacy is "an understanding of the concepts, terminology and operations that relate to general computer use ... [and] the essential knowledge needed to function independently with a computer." Webopedia [5] calls it "the level of expertise and familiarity someone has with computers ... [and] the ability to use applications rather than to program."

While these definitions are generally consistent, they are also extremely vague. A more comprehensive specification of computer literacy skills was discussed by Eisenberg and Johnson [6]. Their list of computer skills includes: knowing the parts of a computer, writing documents with a word processor, searching for information on the World Wide Web, using email, generating charts, using electronic spreadsheets, creating electronic slide shows, creating World Wide Web pages, and many more. Additionally, other authors, such as Wolfe have noted that, "no computer user should remain unaware of the ethical and social responsibilities inherent in employing electronic technology [7]." This more comprehensive and responsible definition of computer literacy requires the determination of whether students are developing an understanding of the impacts of computers on society.

Finally, in a report [8] issued by the Committee on Information Technology Literacy sponsored by the National Academy of Sciences a comprehensive discussion of computer literacy is undertaken. In that discussion the committee concludes that fluency in information technology is dependent on the specific educational context. For example, the content of a course for teaching information technology to history majors might be quite different than a similar course for engineers. Effectively assessing a course in computer literacy requires an understanding of the context in which the course is being taught.

Proceedings of the 2002 American Society for Engineering Education Annual Conference \& Exposition Copyright $\odot$ 2002, American Society for Engineering Education 


\section{Background}

CSUN, established in 1956, is one of 22 campuses in the California State University system. With an enrollment of over 31,000 students, CSUN is the only four-year institution of higher education committed to responding to the needs of the multicultural community of the San Fernando Valley. CSUN faculty and its student body echo the diversity of its community, with a student population that is 23\% Latino, 7.5\% African American, and 13.1\% Asian and Pacific Islander [9]. CSUN is a federally designated Minority Serving Institution (MSI) and Hispanic Serving Institution (HSI).

The University Assessment Program at CSUN, now in its tenth year, began in 1991 when the University started implementing systematic outcomes assessment. A formal assessment policy followed in 1995, the purpose of which is to facilitate the highest quality educational experience for students through the systematic collection and use of data to improve curriculum and student learning outcomes. The university is also collaborating on a national study conducted by the Consortium of Assessment and Policies (CAPS) to assess basic skills in General Education. The experimental effort to assess CSUN's computer literacy course was undertaken in support of that study.

\section{Project Goal}

The goal of this project was to evaluate an instrument for assessing student learning outcomes of Computer Science 100 (CS 100). CS 100, Computers: Their Impact and Use, is a General Education course taught at CSUN to give students an overall background in the use of computers. Since teaching computer literacy is an important goal at the University, our major aim was to find an instrument that would be effective in assessing this course. The CSU Chancellor's Office asked some of the campuses to examine the effectiveness of a particular instrument, called Tek.Xam [10], for this purpose, and we agreed to undertake a pilot study.

\section{Methods}

Two courses, Computer Science 100 and Journalism 100 (Mass Communication) were selected for this study, and pre and post examinations were given to students in each. Students took exactly the same examination for the post test as they took for the pre test. Students from the Journalism 100 course were chosen to serve as a control group since this course and CS 100 fulfill the same general education requirement. It was, therefore, considered unlikely that students selecting Journalism 100 would also take a course in computer literacy, making the groups disjoint. Four CS 100 sections from different times and days were selected to reduce any possible effect due to time of day or day of the week. The study was designed and implemented by two Computer Science Professors and one Health Science Professor who is also the Coordinator of University Outcomes Assessment. 


\section{The Instrument}

Tek.Xam was the instrument used to assess computer literacy in the pilot study. According to the Virginia Foundation for Independent Colleges [11], the Tek.Xam measures technology and problem-solving skills within the technology environment. It is an Internet-based, vendor-neutral* test delivered online in a proctored computer lab. The instrument's main objective is to provide student credentials or certification of technology proficiency and problem solving skills to prospective employers. It is composed of five modules each taking approximately one hour to complete. The five modules include: general computer concepts, web page creation, presentation preparation, spread sheet concepts and word processing. These five modules constitute much of the basic content of CS 100.

Because of the total length of the exam (five hours) it was decided to have each student take only one module. Students were assigned modules in a random manner, and it was, therefore, necessary to develop a matrix and record which test each student had taken in the pre test so that they would have the same module for the post test at the end of the semester. Students were given the pre test in the second and third weeks of the semester and the post test in the last two weeks of the semester. The paired $t$ test was used to determine whether there was a difference in the pre and post test results on the Tek.Xam.

\section{Results}

One hundred thirty nine students took the pre test. Thirty one were from Journalism and one hundred eight from Computer Science. Only fifty one of the students who took the pre test also completed the post test. The attrition rate was higher in Journalism. Only five out of thirty one $(16 \%)$ completed the post test.

\begin{tabular}{|c|c|c|c|}
\hline & Pre Test & Post Test & Percent completing both tests \\
\hline Journalism & 31 & 5 & $16 \%$ \\
\hline Computer Science & 108 & 46 & $43 \%$ \\
\hline Total & 139 & 51 & $37 \%$ \\
\hline
\end{tabular}

Since only five of the journalism students completed the test, they were not included in the analyses.

One student passed module 1 of the exam in the pre test and one passed module 2 . Thirteen Computer Science 100 students took both the pre and post test for module 1 of the exam which tested general concepts. There was a statistically significant difference between the pre and post test results $(\mathrm{t}=3.86 \mathrm{p}<0.01)$

* Vendor-neutral means the instrument is not bounded to a particular software application. Most assessment tools are bound to applications from a specific vendor. For example, Microsoft Certifcation tests only Microsoft applications.

Proceedings of the 2002 American Society for Engineering Education Annual Conference \& Exposition Copyright $(\mathrm{C}$ 2002, American Society for Engineering Education 
Only three CS 100 students completed both the pre and post test for module 2 which tested Web page creation. The difference between the pre and post test was not significant.

Four students completed the pre and post test for module 3 which tested presentation preparation. There was a statistically significant difference between the pre test and the post test $(\mathrm{t}=12.5, \mathrm{p}<0.001)$.

Sixteen students from CS 100 completed the pre and post test for module 4 which tested spreadsheet concepts. There was a statistically significant difference between the pre and post test results $(\mathrm{t}=6.89, \mathrm{p}<0.001)$.

Ten students from CS 100 completed the pre and post test for module 5 which tested word processing. Due to technical difficulties at Tek.Xam we were unable to attain valid scores for the post exam.

\begin{tabular}{|c|c|c|c|}
\hline Module & Subject & $\begin{array}{c}\text { Number of students with } \\
\text { pre and post tests }\end{array}$ & $\mathrm{P}$ value \\
\hline 1 & General Concepts & 13 & $\mathrm{P}<0.01$ \\
\hline 2 & Web Page Creation & 3 & $\mathrm{p}>0.05$ \\
\hline 3 & Presentation Creation & 4 & $\mathrm{P}<0.001$ \\
\hline 4 & Spreadsheets & 16 & $\mathrm{P}<0.001$ \\
\hline 5 & Word Processing & 10 & Data unavailable \\
\hline
\end{tabular}

\section{Discussion}

The results that we obtained from the exam indicate that the CS 100 course significantly improves the computer skills in some areas. However, there were too few students who participated in both pre and post test to draw any strong conclusions. We do not believe that the Tek.Xam instrument is the appropriate tool for assessing the learning outcomes for this course for several reasons. Because the Tek.Xam instrument was not user friendly, many students had difficulty understanding how to submit or record their answers after they had completed an exercise. It was difficult for students to navigate through the exam in either direction. In many cases the instructions were unclear or difficult to understand. These factors made taking the exam a frustrating experience that may have contributed to the failure of large numbers not taking the post exam. In addition, because the test was not mandatory, and the post test occurred close to the end of the semester, many students chose not to participate. The inability to get students who took the pre test to also participate in the post test may have affected the reliability of the results.

Since the exam was web based, the responsiveness from the host server was highly variable. In one instance when the exam was being administered, the host stopped responding for a considerable amount of time, and students could not proceed at all. This added to the student 
frustration and may have possibly affected the results. Since the variability of the response affected how quickly the students could proceed through the exam, it could have affected their individual scores. Another major problem was that Tek.Xam did not adequately measure the learning objectives for CS 100. While the objective of the Tek.Xam is to certify students at a high level of competence in computer skills, insuring that they are ready for the job, the CS 100 objective is to provide students with an overall background in the use of computers. Therefore, the CS 100 expected level of proficiency is not how fast a student can perform a task but whether or not the student can perform the task at all; Tek.Xam measures a mastery of skills while CS 100 only introduces students to concepts and applications. In general, it was found that Tek.Xam expected a higher level of proficiency than that expected from CS 100 students. Only about 20\% of the students received a passing score on their module of the Tek.Xam post test.

Additional problems were faced in the administration of the Tek.Xam. The set up of the application was tedious and rigid with not enough real time feedback when entering the data for registering students. For example, the date of birth was only accepted in a non standard format. The student id was a combination of case sensitive letters and numbers. It was difficult to differentiate zero from the letter "O" and the lowercase letter "l" from a one. Management of student data was not intuitive, and there was no online reference manual. TekXam has announced that they are working with Brainbench, Inc. to develop an improved version of the exam, which will be more suitable for assessment purposes [12].

There exist many other instruments to assess computer literacy skills. Some of them are Web based; others run in networked environments. Many of these assessment tools have been created to support specific textbooks such as SAM (Skill Assessment and Measure) from Thomson Learning [13]. Similar instruments are provided by other publishing companies. Other assessment vehicles, such as SkillDrill, provide certification for specific software applications [14]. All of these instruments are not only vendor-specific assessment but designed to assess a specific skill, such as word processing, Web page creation, or use of spreadsheets. Tek.Xam on the other hand offers a vendor neutral environment and includes the areas specified in most of the computer literacy definitions. Although it has shortcomings, Tek.Xam may be the most generally useful computer literacy assessment tool currently available.

\section{Conclusion}

Teaching computer literacy is important, and assessment is needed to measure how well the institution is meeting this objective. Using the Tek.Xam instrument we were able to show that our students do profit from their exposure to CS 100. However, a more appropriate, user friendly tool is needed to fully assess whether the course objectives are being met. Since the meaning of computer literacy varies considerably depending on field where it is required, it is difficult to apply a single standardized assessment instrument in all situations. It seems, unfortunately, to be the case that assessing computer literacy requires the development of specific instruments tuned to 
the particular objectives of the course being evaluated.

One of the major difficulties encountered in this pilot study was getting students who had taken the pre test to also take the post test. It is clear that some type of reward is necessary to encourage students to complete the post test. Giving some credit towards the course grade for participation in both the pre and post tests might be an appropriate reward. This issue will be examined further in the next study.

Our future plans are to develop a specific evaluation instrument for CS 100 and to conduct a comprehensive assessment for this basic level of computer literacy. We also plan to review the engineering curriculum, identify computer skills and knowledge needed at this level, and appropriately modify the basic computer literacy assessment instrument for the field of engineering. We will then use this assessment vehicle to evaluate our success in preparing engineering students with the computer skills necessary to be successful in this field of study.

Bibliography

1. About the Digital Divide: Access (2001). Digital Divide Network. Retrieved November 5, 2001 from the World Wide Web: http://www.digitaldividenetwork.org/content/sections/index.cfm

2. Falling through the Net: Toward Digital Inclusion, A Report on Americans' Access to Technology Tools (2000. A Report of the U.S. Department of Commerce, Washington, D.C.

3. Webster's II New College Dictionary (1999). Houghton Mifflin Co., Boston.

4. Stewart, Bill. Computer Literacy Issues: Definition \& FAQ. Retrieved November 1, 2001 from the World Wide Web: http://www.virtualbill.net/qamain/qamain.html.

5. Computer Literacy. Retrieved November 1, 2001 from the World Wide Web: http://www.webopedia.com/TERM/C/computer_literacy.html.

6. Eisenberg, Michael B., Johnson, Doug. Computer Skills for Information Problem Solving: Learning and Teaching Technology in Context. Eric Digest: Clearinghouse on Information \& Technology, EDO-IR-96-04. March 1996. URL: http://ericit.org/digests/EDO-IR-1996-04.shtml.

7. Wolfe, H.W. (1992). Computer Literacy for the 1990s. Journal of Information Systems Education. 4:1.

8. Committee on Information Technology Literacy, National Research Council (1999). Being Fluent with Information

Technology. National Academy of Sciences.

9. Office of Institutional Research (2000). California State University, Northridge Factbook: Academic Year 1999/2000, 16. California State University, Northridge. Northridge, CA.

10. Tek.Xam: The Nationwide Standard for Technical Literacy. Virginia Foundation for Independent Colleges. Retrieved January 10, 2002 from the World Wide Web:http://www.tekxam.com.

11. Tek.Xam: The Technology Certification Exam. Virginia Foundation for Independent Colleges. Retrieved January 10, 2002 from the World Wide Web: http://www.vfic.org/programs/tekxam/index.htm.

12. Brainbench: The Measure of Achievement. Retrieved January 15, 2002 from the World Wide Web: http://www.brainbench.com.

13.Sam 2000. Course Technology, Thompson Learning. Retrieved January 14, 2002 from the World Wice Web: http://www.course.com/assessment/sam2000.

14. SkillDrill. BrainBuzz.com. Retrieved January 14, 2002 from the World Wide Web:http://www.skilldrill.com.

Proceedings of the 2002 American Society for Engineering Education Annual Conference \& Exposition Copyright (C) 2002, American Society for Engineering Education 
ROBERT LINGARD

Robert W. Lingard is an Assistant Professor of Computer Science for the College of Engineering and Computer Science at California State University, Northridge. He is also chair of the Academic Technology Committee of the Faculty Senate and is actively involved in research in the area of software engineering education. Dr. Lingard received his B.A. and M.A. in Mathematics from the University of California, Los Angeles and his Ph.D. in Computer Science from the University of Southern California.

\section{ROBERTA MADISON}

Roberta Madison is a Professor of Health Sciences for the College of Health and Human Development at California State University Northridge. She is the Coordinator of Outcomes Assessment for the University. Dr. Madison received her B.A. and M.A. in History from the University of California, Los Angeles, and her M.S. and Dr. in Public Health from University of California, Los Angeles.

\section{GLORIA MELARA}

Gloria Melara is an Associate Professor of Computer Science for the College of Engineering and Computer Science at California State University, Northridge. She is Coordinator of the Computer Literacy program, member of the Academic Technology Committee of the Faculty Senate and her areas of interest are multimedia and educational computing research. Dr. Melara received her B.A. in Mathematics from Universidad Nacional de El Salvador, El Salvador, her M.A. in Mathematics and M.S. in Computer Sciences from Western Michigan University, Kalamazoo Michigan, and her Ph.D. in Instructional Systems Technology from the University of Southern California. 